\title{
Cinco colombianos en el exterior, cinco experiencias de emprendimiento Re-construcción de la condición social de inmigrante a partir de la creación de pequeñas y medianas empresas
}

\author{
María Juliana Ruiz ${ }^{1}$ \\ maju_ruiz@hotmail.com
}

Artículo de investigación científica y tecnológica recibido el 09/02/2011 y aprobado el 10/06/2010

\section{Resumen}

El fenómeno de las migraciones internacionales en Colombia ha venido cobrando fuerza durante las dos últimas décadas. Se puede observar que, como resultado de lo anterior, se han incrementado considerablemente los flujos de colombianos al exterior; así mismo, se han modificado los destinos, las motivaciones y las condiciones socio-económicas de aquellos que emprenden dicho proceso. Paralelamente se han desarrollado estudios que se encargan de, por un lado, describir y caracterizar a la población colombiana por fuera del país; y por otro lado, analizar las motivaciones de partida y los efectos de las migraciones de carácter internacional en dos escenarios: un primer escenario estructural de los sistemas político,económico y social - tanto del Estado de acogida como del colombiano-y un segundo escenario de corte personal representado por el círculo social en el que se desenvuelve el inmigrante. Ahora bien, bajo este panorama existen diversas formas bajo las cuales los colombianos en el exterior logran integrarse de manera efectiva a la sociedad receptora a la vez que mantienen relaciones con sus comunidades de origen; la creación de pequeñas y medianas empresas se perfila como uno de éstos mecanismos bajo los cual el inmigrante puede re-construir sus condiciones sociales e incrementar los niveles de aceptación en la sociedad de acogida.

Palabras clave: Sociedad receptora, capital económico, capital social, capital político, Estado, trans-nacionalismo, inmigrante, PYMEs.

1 Graduada en Ciencia Política con énfasis en Relaciones Internacionales de la Universidad Icesi. Actualmente trabaja para una firma consultora en marteking político en Bogotá. 


\begin{abstract}
The phenomenon of international migration in Colombia has been gaining force over the past two decades. As a result, there has been an increase of the flow of Colombians abroad; and, at the same time, the destinations, motivations, and socio-economic conditions of those who are making part of this process are changing. The researchers in Colombia have been concentrating their attention on two tasks: on one hand, to describe and characterize the Colombian population outside the country, and, on the other hand, to analyze the motivations and impacts of international migration in two scenarios: one scenario composed of the political, economic, and social structures of both states (the host State and the colombian State); and, the other, a more personal one, represented by the social circle in which the migrants actually live their lives. In this context, there are many ways in which the Colombian migrants are able to integrate effectively into the host society while maintaining relations with their home communities; the creation of small and medium enterprises are emerging as one of these ways through the immigrant can re-build their social conditions and increase the level of acceptance by the host society.
\end{abstract}

Key words: International migration, host society, social capital, politic capital, economic capital, State, transnationalism.

\title{
Preámbulo
}

$\mathrm{E}$ n Colombia las migraciones internacionales no parecen ser ajenas a la realidad, por el contrario, si estudiamos detenidamente el árbol genealógico de cualquier colombiano, a excepción de algunas comunidades indígenas o autóctonas, un porcentaje considerable presentaría el siguiente panorama: esposos, hermanos, padres e hijos migran a diferentes países y ciudades; se establecen y construyen su historia en lugares lejanos a los de su origen y se nutren de las raíces de su nacionalidad. Ahora bien,la migración internacional de colombianos ha aumentado considerablemente durante las últimas décadas y se han diversificado los lugares de destino y las causas de la migración. Según estimaciones del DANE, en 1990, cerca de 1,7 millones de colombianos se encontraban en el exterior, ascendiendo en 2003 a 2,7 millones de personas. Sin embargo, el cambio significativo tuvo lugar en 2005 cuando en el censo de ese mismo año se registraron 3,3 millones de emigrantes (cerca del ocho por ciento de la población colombiana). Por otro lado, ha aumentado significativamente el peso de las remesas en la economía colombiana como resultado del incremento de los flujos migratorios de colombianos al exterior. La Organización Internacional para la Migración (OIM) afirma que en 2008, los colombianos radicados en el exterior aportaron a la economía nacional cerca de 4,884 millones de dólares a través de las remesas, cifra que creció a una tasa del catorce por ciento en el periodo de 2000 al $2007^{2}$.

2 Comunidad Andina, Secretaría General, Estadisticas de Remesas de la Comunidad Andina (2000 - 2007), Documento Estadístico, Octubre de 2008, p.2. 
Bajo este panorama, no es extraño encontrar restaurantes colombianos en las grandes ciudades del mundo; por ejemplo: Nueva York, París, Barcelona, Santiago y Sao Pablo gozan actualmente de dichas sucursales gastronómicas. Sin embargo, éste fenómeno no se debe a la creciente popularidad de la comida colombiana o a la expansión de una cadena de productos alimenticios típicos de Colombia.Se debe, en cambio, a un aumento considerable de los flujos migratorios de colombianos al exterior, quienes realizan diferentes actividades económicas de emprendimiento, tales como peluquerías, restaurantes, agencias de viajes, comercializadoras de productos nacionales, entre otros. No es fortuita entonces la internacionalización de productos y servicios de colombianos; son resultado de las diferentes actividades emprendedoras de nacionales en el exterior que utilizan las relaciones transnacionales entre Colombia y el país de receptor para el establecimiento de diferentes empresas, como en el caso de las “sucursales” gastronómicas. Por otro lado, ante el reducido universo de oportunidades laborales al que tienen acceso los inmigrantes colombianos - aunque cabe aclarar que esta situación no se da en la totalidad de los casos- el emprendimiento de proyectos productivos sostenibles aparece como una opción viable para el sustento económico; se requiere de un capital semilla considerablemente pequeño para el inicio de las actividades, lo cual aumenta las posibilidades de desarrollo de las mismas. No obstante, se debe aclarar que el capital económico no garantiza el éxito de la actividad emprendedora, son necesarios diversos factores (como el capital social, el contexto económico, la coyuntura política, el sistema político, entre otros) que se entrecruzan y mezclan y que arrojan como resultado pequeñas y medianas empresas consolidadas; o bien, por el contrario, efímeras experiencias de emprendimiento.

Lo anterior nos permite observar la manera como la creación de pequeñas y medianas empresas aparece como la forma de empleo que los colombianos utilizan en el exterior, sin embargo, la relevancia de las PyMEs va más allá de éste hecho.A través de éstas el inmigrante 1) mejora las condiciones económicas en las que se encuentra y promueven el desarrollo económico local; 2) establece relaciones sociales con la comunidad receptora que facilitan su asimilación e integración a la misma,y 3) posibilita, o aumenta, su visibilización política. En primer lugar,en cuanto al ámbito económico, las PYMES adquieren progresivamente importancia, fundamentalmente gracias al empleo que generan en un contexto donde conviven dos situaciones simultáneas: por un lado, una creciente demanda de empleo (de baja calificación) por parte de los jóvenes que cada año se integran a la población económicamente activa (PEA) y por otro lado,la imposibilidad del sector moderno de la economía de absorber esa creciente demanda [Zevallos, 2006]. Bajo este contexto las PyMEs permiten a los inmigrantes participar en el fomento de la economía del país receptor a través de la generación de empleo, dinamización de la economía,inversión de capitales, desarrollo local y aumento del poder adquisitivo del empleador y sus empleados. En cuanto al sistema colombiano el fomento de la economía se da a través de la recepción de remesas y la configuración de redes 
transnacionales comerciales (de presentarse esta situación). En segundo lugar, en el ámbito social, la re-configuración del inmigrante a través de la creación de PyMEs se da por medio de las redes sociales que se construyen alrededor de la empresa. Estas redes pueden ser de carácter local o transnacional; pero en ambos casos desarrollan el capital social del inmigrante, a la vez que le otorgan cierto grado de reconocimiento. Por último, en tercer lugar, en cuanto a la re-configuración política, el inmigrante empresario cuenta con mayor reconocimiento y representación en el ámbito político y legal; adquiere relevancia económica y social en la medida que impacta, de manera directa o indirecta, el desarrollo de la comunidad donde se encuentra ubicado; así mismo aumenta su margen de maniobra dentro del sistema político local del país receptor y nacional del país de origen como resultado del aumento de su reconocimiento público.

Sin embargo,las pequeñas y medianas empresas constituyen un campo poco explorado desde el cual vale la pena estudiar los procesos migratorios de colombianos en el exterior y que se perfila como un potencial de oportunidades sociales, económicas y políticas del inmigrante. Así pues, es menester en esta investigación hacer frente a lo anterior, para lo cual se propone el desarrollo de la siguiente hipótesis: la puesta en marcha de pequeñas y medianas empresas por parte de los inmigrantes empresarios, seleccionados para la investigación, permite a éstos incrementar los niveles acumulados de capital de carácter económico, social y político que afecta la manera como se configura la categoría de "inmigrante" para dichos empresarios. "Categoría” se entiende como: la condición social de unas personas respecto de las demás ${ }^{3}$, la cual se construye bajo procesos de socialización y prácticas culturales entre los inmigrantes, la comunidad de origen y la comunidad receptora; de manera que su significado depende de los imaginarios y/o representaciones sociales que de dicha condición se construyan socialmente.

Esta investigación tiene como objetivo general analizar los procesos bajo los cuales la creación de pequeñas y medianas empresas, por parte de los inmigrantes colombianos seleccionados para la investigación, permite a éstos la acumulación de capital de carácter económico, social y político que afecta la manera como se configura la categoría de "inmigrante" para dichos empresarios. Como objetivos específicos se plantean: 1) identificar las variables determinantes para la reconfiguración de la categoría inmigrante a partir de la creación de pequeñas y medianas empresas para los casos escogidos, teniendo como punto de análisis las categorías de capital económico, capital social y capital político, estableciendo tendencias y desviaciones entre los casos de estudio, y 2) analizar los procesos de acumulación de los tres capitales ${ }^{4}$ mencionados anteriormente en las historias de vida de los emprendedores de estudio, haciendo especial énfasis en la acumu-

3 Real Academia Española, Diccionario de la Lengua Española. Obtenido en http://buscon.rae.es/draeI/ SrvltConsulta?TIPO_BUS=3\&LEMA= categor $\%$ C3\%ADa.. consultado el 18 de octubre de 2010. Consultado el 18 de octubre de 2010

4 Acojo la definición de capital desarrolla por Pierre Bourdieu "el capital es trabajo acumulado, bien en forma de materia, bien en forma interiorizada o incorporada", p.131, Poder, Derecho y Clases Sociales. 
lación de capital político de los mismos. De manera transversal a la investigación se analizarán las redes transnacionales que los casos seleccionados configuraron; particularmente observando si éstas determinaron el resultado final de la experiencia de emprendimiento; o si por lo contrario la creación de pequeñas y medianas empresas fortaleció o creó nuevas redes transnacionales.

La metodología utilizada para el desarrollo de los objetivos de investigación fue de carácter inductivo y cualitativo. Esta contó con tres ejes fundamentales de acción: un primer eje descriptivo, un segundo eje de trabajo de campo, y un tercer eje de carácter interpretativo y analítico. Por otro lado, los cinco casos fueron seleccionados teniendo en cuenta la representatividad de los mismos, según los siguientes criterios: (1) el número de empleados que manejan, el cual es superior a diez personas e inferior a doscientas, (2) la trayectoria histórica de la empresa, la cual para todos los casos es mayor a dos años, (3) la construcción y/o fortalecimiento de redes transnacionales alrededor de la PYME,(4) el reconocimiento político, económico y social de los empresarios de estudio frente a la sociedad receptora y la comunidad colombiana en el país receptor; y por último (5) las relaciones de estos empresarios con el gobierno colombiano (para este caso los consulados). Los casos analizados están ubicados en diferentes países lo cual ofrece una mirada más amplia sobre los diferentes procesos de asimilación y/o integración a la sociedad receptora y las diferentes configuraciones de la categoría "inmigrante" en diferentes contextos; es decir, el significado que adquiere esta ca- tegoría social en diferentes ámbitos. Así mismo, cada historia de emprendimiento da cuenta de los diferentes motivos de partida de los inmigrantes colombianos y responde a características particulares de las condiciones sociales, políticas y económicas de cada uno de ellos; de manera que, cada caso de estudio se encuentre diferenciado, pero conserva variables que permiten su comparación y la identificación de tendencias.

Ahora bien, para el análisis de la reconfiguración de la categoría de inmigrante de los empresarios seleccionados, se tuvo en cuenta lo siguiente:

Primero, para efectos de esta investigación, se parte del siguiente supuesto hipotético para el significado de "inmigrante": en el momento en que el individuo llega al país receptor (para este caso los colombianos seleccionados) (a) la categoría cuenta con connotaciones negativas en la medida que, para la mayoría de los casos, se considera al inmigrante como un problema social ${ }^{5}$,(b) el inmigrante cuenta con pocas relaciones sociales en el país receptor, bajo capital social,económico y político y (c) el inmigrante se encuentra al margen del sistema social, con una capacidad de maniobra reducida dentro del mismo e integrado parcialmente, o en algunos casos con ningún nivel de integración.

Segundo, una vez se ha consolidado la PYME el significado de la categoría "inmigrante" cambia para los empresarios involucrados en la medida en que generan empleo, dinamizan la economía local,y

5 CAVALCANTI, Leonardo. El papel del protagonismo empresarial latinoamericano en la (re)construcción social de la categoría 'inmigrante' en España. en, Papers: revista de sociología, ISSN 0210-2862, № 85 , 2007 , pags. $177-191$. 
del país de origen con el envío de remesas, fomentan el desarrollo regional y por último, fortalecen su capital social y las redes transnacionales que se construyen alrededor de ellos.

Por otro lado, para la clasificación de la información se identificaron tres etapas en el proceso de la re-configuración de la categoría "inmigrante": momento de llegada pre-montaje de la PYME, proceso de formación de la PYME, y un tercer momento post-PYME o etapa de reconocimiento político. En cada una de las etapas se analizaron los siguientes componentes: el capital social, económico y el capital político; de manera que se corroborara la hipótesis de investigación. Sin embargo, en este punto se debe tener en cuenta lo siguiente: debido a las limitaciones técnicas ${ }^{6}$ del proyecto de investigación, se estudiará la re-configuración de la categoría de inmigrante exclusivamente para los casos de estudio teniendo en cuenta las percepciones personales de los empresarios respecto al tema; así pues, las conclusiones que se hallen al final del documento serán aproximaciones parciales respecto al tema. Frente a lo anterior, presento la pregunta de investigación: ¿de quémanera las pequeñas y medianas empresas de colombianos en el exterior re-configuran la categoría de inmigrante para el caso de cuatro experiencias exitosas de emprendimiento ${ }^{7} y$ una quinta experiencia de contraste de fracaso

6 Durante el levantamiento de la información sobre el estado de las cosas, se tuvo inconvenientes en el acceso a la información por parte de las entidades estatales las cuales limitaron el acceso a las mismas. 7 Entendiendo como experiencias exitosas de emprendimiento a todas aquellas pequeñas y medianas empresas que se hayan consolidado como tal, que tengan un mínimo de dos años de historia y que cuenten con cierto reconocimiento social en la ciudad en la que se encuentren. ubicados en Australia, Estados Unidos, Perú yel Reino Unido?

El marco teórico para el desarrollo de la investigación se estableció tomando como punto de partida las diferentes teorías para el estudio de las migraciones internacionales, poniendo especial énfasis en el análisis transnacional del fenómeno migratorio. Así mismo tomo como referencia los conceptos de capital económico, social y capital político; y redes sociales para entender la manera como las pequeñas y medianas empresas re-configuran el estatus de inmigrante tomando como referencia consideraciones pertinentes acerca de la relación emprendimiento-migración y pequeñas y medianas empresas.

Cinco historias de vida, cinco experiencias de emprendimiento: presentación de los casos de estudio. Cinco colombianos radicados en el exterior son los encargados de darle pies y cabeza a ésta investigación, sus historias de vida como emigrantes emprendedores constituyen los insumos que, sumados a los lineamientos teóricos planteados anteriormente, pondrán a prueba la hipótesis del trabajo. Los casos ilustrativos que se tomaron como referencia para la investigación se clasificaron según las siguientes variables: nombre o seudónimo con el cual se identificará a cada empresario, edad, país receptor, razones por las que se encuentra en ese lugar y no en otro, nivel de escolaridad, caracterización socio-demográfica de su vida en Colombia y, por último, los argumentos presentados que motivaron, o determinaron la decisión de partida. Así mismo, se presentan en este apartado las 
características generales sobre las PYMES correspondientes.

A continuación se presenta a los empresarios seleccionados como casos de estudio.Cuatro de ellos corresponden a experiencias de éxito empresarial, la quinta de esas personas corresponde al caso de contraste o "fracaso"; adoptando aquí el significado del diccionario de La Real Academia de la Lengua Española el cual define al fracaso como "resultado adverso de una empresa o negocio". Así mismo, respetando la identidad de los empresarios, se utilizarán seudónimos para referirse a ellos.

\section{Experiencias de éxito}

Martha: mujer de 45 años de edad, radicada en Lima, Perú desde el año el 2001. Es originaria de Bogotá y estudió ingeniería de sistemas en la Universidad de los Andes. En Colombia trabajaba para una empresa en el área de sistemas en la ciudad de Bogotá, vivía con su único hijo y no participaba en política o en alguna organización social. Los factores que determinaron su residencia en Lima constituyen a factores externos a ella en primera instancia, puesto que la empresa para la que trabajaba decidió trasladarla a esta ciudad por motivos laborales; sin embargo, en segunda instancia Martha, una vez culminado el proyecto en esta ciudad decidió quedarse en Lima puesto que veía oportunidades de negocio en el área de sistemas que ella manejaba.

Mario: nació en Bogotá Cundinamarca, tiene 31 años de edad y residió en Sídney, Australia, desde el año 2001 hasta enero de 2010, actualmente se encuentra en Colombia hasta finales de año cuando retornó a Australia. Es administrador de empresas y tiene una maestría en ingeniería de sistemas. En Colombia, antes radicarse por fuera del país, estudiaba en la Universidad Externado; no participaba en política - entendida esta como participación en partidos políticos- o hacía parte de alguna organización social. Decidió hacer un intercambio estudiantil con una universidad en Australia, $y$ posteriormente decidió trasladarse a ésta universidad y terminar sus estudios de pregrado en ella; terminados sus estudios de administración de empresa decidió quedarse en el país para realizar su maestría y empezar su propia empresa.

Jaime: administrador de empresas con postgrado en comercio internacional de la Universidad EAN.Nació en Zipaquirá, Cundinamarca, tiene 43 años y actualmente vive un Houston, Texas (Estados Unidos) desde el año 2000 cuando por motivos de seguridad tuvo que salir del país. En Colombia trabajó para agencias de seguridad del Estado y no participaba en política o hacía parte de alguna organización social. Tras el inconveniente personal en materia de seguridad que tuvo en Colombia, decidió ir a "probar suerte" a Nueva York donde tenía un familiar, sin embargo, en esta ciudad fue víctima de varias experiencias de rechazo por lo que decidió ubicarse en otra parte; probó con un par de ciudades hasta radicarse definitivamente en Houston donde tenía amigos que le facilitaron las cosas.

Roberto: nació en Cocorna,Antioquia, en 1951, actualmente tiene 59 años, es divorciado y vive en Londres, Reino Unido. Salió del país en el año 1976 a la edad de 25 años. En Colombia trabajaba como ingeniero textil en Coltejer en el área de control de calidad en una fábrica ubicada 
en Rionegro. Roberto decidió renunciar a su trabajo en Colombia, retirar sus ahorros y financiar un tiquete en búsqueda de "aventura" (como lo afirmó en las entrevistas). La idea original consistía en llegar a Suecia donde se reuniría con sus amigos; sin embargo, esto no se dio así y su primera parada fue en Bélgica. Finalmente no se reunió con sus amigos en Suecia,y luego de pasar por Francia y España,decidió vivir en UK motivado nuevamente por las sugerencias de algunos amigos que se encontraban ahí.

\section{Experiencia de fracaso}

Juan: nació en Cali, tiene 31 años y actualmente vive en Miami, Florida (Estados Unidos) desde el año 1999. Hizo tres semestres de administración de empresas en la Universidad San Buenaventura, sin embargo, consideraba que en Cali no había oportunidades para él por lo que decidió irse a Estados Unidos a "hacer plata”. En Colombia vivía con sus padres y hermano en Cali, no hacía parte de alguna organización social o participaba en política (entendida, al igual que en los anteriores casos, como la vinculación en actividades de partidos políticos); era como él define, “un joven normal”. Llegó primeramente a Washington, donde vivía un familiar, posteriormente se trasladó a Miami, donde vivían unos amigos.

Bajo este panorama aparecen las pequeñas y medianas empresas de los inmigrantes seleccionados, éstas fueron clasificadas según 6 criterios: sector al que pertenecen, tipo de empresa, año en el que fueron fundadas, número de trabajadores, comunidad a la que están dirigidos sus productos y/o servicios y nacionalidad de los trabajadores.
Se observa que, según las entrevistas realizadas, para los casos de éxito, la idea de la PYME nace de la acumulación de capital social y económico y de experiencia laboral en el campo. Sin embargo, se observa que para el caso de "fracaso" la idea de la PYME surge por una oportunidad de negocio,pero sin experiencia en el tema; de manera que la mayoría de los casos de estudio justifican el tipo de empresa en la experiencia laboral que tenían en el campoy en capacitaciones previas frente al tema. Así mismo, la mayoría (y con esto hago referencias a Martha, Roberto y Mario) coincide en que un porcentaje considerable de sus empleados son colombianos pero, aseguran que no hay ningún tipo de preferencia frente a esto. Aquí en este punto aparecen algunas contradicciones, si bien no existen preferencias, en todas las narraciones aparece un elemento patriota y de nostalgia. Así mismo, la clientela de los empresarios escogidos es variada y no existe una segmentación del mercado a colombianos. Sin embargo sí existe un porcentaje mayor de colombianos dentro de sus clientes (a excepción del caso de Juan donde la comunidad colombiana en el exterior representa un porcentaje mínimo de su clientela). En este punto es importante resaltar la capacidad innovadora de las PYMES seleccionadas, en cuanto que todas desde la condición de inmigrante de los dueños y creadores ofrecen servicios y/o productos con valor agregado que permiten su posicionamiento. En cuanto a lo anterior, Pablo Orlandi afirma que "la capacidad innovadora es sin lugar a dudas una de las características más interesantes de las PYMEs. Recordemos, por ejemplo,durante la década pasada,el 


\begin{tabular}{|c|c|c|c|c|c|c|}
\hline $\begin{array}{l}\text { clasificación } \\
\text { PYME } \\
\text { Nombre }\end{array}$ & $\begin{array}{l}\text { Sector al que } \\
\text { pertenecen }\end{array}$ & Tipo de empresa & $\begin{array}{l}\text { Año de } \\
\text { fundación }\end{array}$ & $\begin{array}{l}\text { Número de } \\
\text { trabajadores }\end{array}$ & Clientela & $\begin{array}{l}\text { Nacionalidad } \\
\text { de los trabaja- } \\
\text { dores }\end{array}$ \\
\hline \multicolumn{7}{|c|}{ Experiencias de éxito } \\
\hline Roberto & Comercio & Restaurante & 1991 & 10 & $\begin{array}{l}\text { Principalmen- } \\
\text { te latinoame- } \\
\text { ricanos }\end{array}$ & $\begin{array}{l}\text { Principalmente } \\
\text { latinoamerica- } \\
\text { nos }\end{array}$ \\
\hline Jaime & Servicios & $\begin{array}{l}\text { Promotora de se- } \\
\text { guridad }\end{array}$ & 2006 & 35 & $\begin{array}{l}\text { No tiene distin- } \\
\text { ción específica } \\
\text { en cuanto a su } \\
\text { clientela }\end{array}$ & $\begin{array}{l}\text { No tiene distin- } \\
\text { ción en cuanto a } \\
\text { la nacionalidad } \\
\text { de sus trabaja- } \\
\text { dores }\end{array}$ \\
\hline Mario & Servicios & $\begin{array}{l}\text { Agencia de inter- } \\
\text { cambio } \\
\text { estudiantiles }\end{array}$ & 2006 & 12 & $\begin{array}{l}\text { Principalmen- } \\
\text { te colombia- } \\
\text { nos, aunque no } \\
\text { tiene distin- } \\
\text { ción específica } \\
\text { en cuanto a su } \\
\text { clientela }\end{array}$ & $\begin{array}{l}\text { Colombianos en } \\
\text { su totalidad }\end{array}$ \\
\hline Martha & Comercio & Restaurante & 2005 & 25 & $\begin{array}{l}\text { Principalmen- } \\
\text { te colombia- } \\
\text { nos, aunque no } \\
\text { tiene distin- } \\
\text { ción específica } \\
\text { en cuanto a su } \\
\text { clientela }\end{array}$ & $\begin{array}{l}\text { Principalmente } \\
\text { colombianos, } \\
\text { aunque no tie- } \\
\text { ne distinción } \\
\text { en cuanto a la } \\
\text { nacionalidad }\end{array}$ \\
\hline \multicolumn{7}{|c|}{ Experiencia de fracaso } \\
\hline Juan & Servicios & Inmobiliaria & 2003 & 10 & $\begin{array}{l}\text { No tiene distin- } \\
\text { ción específica } \\
\text { en cuanto a su } \\
\text { clientela }\end{array}$ & $\begin{array}{l}\text { No tiene distin- } \\
\text { ción en cuanto a } \\
\text { la nacionalidad } \\
\text { de sus trabaja- } \\
\text { dores }\end{array}$ \\
\hline
\end{tabular}

desarrollo innovador de Internet estuvo en gran medida liderado por PYMEs.También es importante destacar que cuando hablamos de innovación no siempre nos referimos a tecnologías de quiebre, como es el caso de Internet.La innovación puede darse en diversas dimensiones, ya sea a partir del producto que se comercializa, los procesos de fabricación o servicio en general, organizativamente a través de estructuras creativas que promuevan el mejor desempeño de los empleados o a través de la comercialización y el marketing creativos ${ }^{87}$.

8 ORLANDO, Pablo. Las PYMES y su rol en el Comercio Internacional, White Paper Series del Centro de Estudios
Del momento de llegada a la instalación y reconocimiento: proceso de incremento de los niveles acumulados de capitales Para analizar el incremento, o acumulación, de capital económico, social y político de los cinco casos de estudio fue necesario operacionalizar la información recopilada en las entrevistas. Para lo anterior, se delimitaron variables de carácter cualitativo donde cada una de las ellas contenía una serie de propiedades; por tanto durante el estudio se identificará la ausencia o presencia de dichas propiedades.

para el Desarrollo Exportador - CEDEX, Universidad de Palermo, Argentina, 2006, p.4. 
Para el desarrollo de lo anterior se adoptó el concepto de "recurso" el cual comprende la distinción entre, por un lado, los recursos instrumentales los cuales son definidos como recursos específicos que determinados autores usan para realizar sus propios intereses; y del otro lado, los recursos estructurales, los cuales se definen como los que facilitan a diversos actores la persecución de sus intereses mediante el empoderamiento de sus acciones o el acondicionamiento efectivo de los recursos instrumentales [Birner, Wittner, 2000: 5]. Así mismo, la distinción entre los recursos estructurales y los instrumentales da cuenta de las diferencias entre las perspectivas privadas y públicas del capital social [Birner, Wittner, 2000: 6] así como también del capital económico y político.

En la perspectiva privada, el capital político está formado por los recursos que un actor, es decir, un individuo o un grupo, puede disponer y utilizar para influir en los procesos de formación de políticas para llevar a cabo resultados de interés para el actor. Esta definición de capital político corresponde a los recursos instrumentales en la teoría de los recursos políticos. En la perspectiva pública, el capital político se refiere a las variables estructurales del sistema político que influyen en las posibilidades de los diversos actores políticos para acumular capital instrumental y el estado de la eficacia de los diferentes tipos de capital político instrumental ${ }^{9}$.

9 In the private perspective, political capital consists of the resources which an actor, i.e. an individual or a group, can dispose of and use to influence policy formation processes and realize outcomes which are in the actor's perceived interest. This definition of political capital corresponds to the instrumental resources in political resource theory. We
Ahora bien, durante la construcción de las variables e indicadores se tuvo en cuenta lo siguiente: 1) los parámetros estructurales del sistema social y político (la perspectiva pública) determinan qué tipo de capital social de los diversos actores se puede acumular,y quiénes de ellos pueden transformar dicho capital en diferentes formas de capital político (perspectiva privada). 2) Los actores pueden diferenciarse en sus capacidades (emprendimiento, innovación, etc) para encontrar formas eficientes de transformación de capital ${ }^{10}$.Por tanto, las variables e indicadores estructurales dependen del contexto en el que se inscriban y por tal motivo varía según el lugar de residencia de los casos de estudio.Así mismo, como consecuencia del carácter transnacional de estos inmigrantes, las variables se inscriben en una lógica dual de relación simultánea entre la comunidad de origen (el Estado colombiano) y la receptora; haciendo que los márgenes de referencia territorial se desdibujen.

Las variables e indicadores quedaron construidos como se puede apreciar en la Matriz 1.

therefore propose the term "instrumental political capital" to denominate the private perspective... In the public perspective, political capital refers to the structural variables of the political system which influence the possibilities of the diverse actors to accumulate instrumental political capital and condition the effectiveness of different types of instrumental political capital.(Birner, 2000, p.6).

10 The structural parameters of the social and political system (public perspective) determine which type of social capital the diverse actors can accumulate, and to which extent they can transform (invest) it into different forms of political capital (actors' perspective). The actors may differ in their capacity (entrepreneurship, innovativeness, etc.) to find efficient ways of capital transformation, especially when the structural parameters of the political and social systems are changing.(Birner, 2000, p.7). 
Matriz 1: variables, dimensiones e indicadores generales.

\begin{tabular}{|c|c|c|}
\hline Variables & Dimensiones & Indicadores \\
\hline \multirow[t]{2}{*}{ Capital social } & $\begin{array}{l}\text { Perspectiva Pública } \\
\text { (capital estructural) }\end{array}$ & $\begin{array}{l}\text { Variables estructurales del sistema social: } \\
\text { "La ciudad": aceptación o rechazo de la población receptora hacia } \\
\text { la población inmigrante }\end{array}$ \\
\hline & $\begin{array}{l}\text { Perspectiva Privada } \\
\text { (capital instrumental) }\end{array}$ & Redes de familiares, amigos y/o conocidos. \\
\hline \multirow{3}{*}{ Capital político } & $\begin{array}{l}\text { Perspectiva Pública } \\
\text { (capital estructural) }\end{array}$ & $\begin{array}{c}\text { Variables estructurales del sistema político: } \\
\text { El Estado colombiano - representado aquí por la acción del } \\
\text { consulado -: (lo que hace) trámites, programas, actividades o } \\
\text { ayudas. }\end{array}$ \\
\hline & & $\begin{array}{l}\text { El Estado receptor: la posición que asume trámites, programas, } \\
\qquad \text { actividades o ayudas. }\end{array}$ \\
\hline & $\begin{array}{l}\text { Perspectiva Privada } \\
\text { (capital instrumental) }\end{array}$ & $\begin{array}{l}\text { "Yo tenía un amigo(a)": capital social instrumental. } \\
\text { Rentabilidad: alianza "estratégica" con el consulado. }\end{array}$ \\
\hline \multirow{2}{*}{$\begin{array}{c}\text { Capital } \\
\text { económico }\end{array}$} & $\begin{array}{l}\text { Perspectiva Pública } \\
\text { (capital estructural) }\end{array}$ & $\begin{array}{c}\text { Variables estructurales del sistema económico: } \\
\text { La estructura del mercado: oferta y demanda de los servicios y/o } \\
\text { productos. }\end{array}$ \\
\hline & $\begin{array}{l}\text { Perspectiva Privada } \\
\text { (capital instrumental) }\end{array}$ & Bienes y fuentes de ingreso de los inmigrantes. \\
\hline
\end{tabular}

Fuente: creación propia con base en el texto Converting Social Capital into Political Capital. How do local communities gain political influence? A theoretical approach and empirical evidence from Thailand and Columbia de Regina Birner y Heidi Wittner.

Las dimensiones corresponden a los rasgos de las variables que se medirán y que permitieron construir los indicadores. Por su lado,los indicadores señalan cómo medir cada uno de los rasgos o factores de las dimensiones de las variables. Para cada tipo de variable (capital económico, capital social y el político) las dimensiones instrumentales dependen de las dimensiones estructurales. Así mismo, el capital político instrumental aparece como variable dependiente de la formación previa de capital social del mismo tipo, el cual se concibe como variable necesaria para su acumulación; mas no suficiente puesto que depende a su vez de las variables estructurales tanto del sistema social,como del sistema político. La construcción de las variables e indica- dores se basó en la información recopilada por el conjunto de entrevistas realizadas a Juan, Jaime, Roberto, Mario y Martha en el periodo comprendido entre junio de 2010 y septiembre del mismo año.

Ahora bien, durante el desarrollo de las entrevistas la atención recayó sobre los procesos de acumulación de capital de tipo social y político, dejando a un lado las preguntas que explícitamente se refirieran a los procesos relacionados con la acumulación de capital económico (para la comodidad de los entrevistados). Sin embargo, la investigación parte de la premisa según la cual la propiedad de bienes, el sueldo y todas las otras fuentes de ingreso de los cinco casos de estudio [Müller, 1986, p. 166] constituye la base para la obtención de los otros tipos de 
capitales [Bourdieu, 1983, p. 196]. Para la investigación, el capital económico aparece como variable independiente durante el proceso y como condición necesaria para el desarrollo del mismo; en tanto que para llevar a cabo cualquier tipo de actividad (en aras de la acumulación de capital social y político) se requiere de algún tipo inversión monetaria - como puede ser cubrir los costos del transporte o alimentación-; aunque no es de interés de la investigación el análisis de la cuantía invertida durante el proceso. Sin embargo, es importante aclarar antes de continuar que existen ocasiones en las que el capital social puede generar capital económico o incluso hacer que éste no sea tan necesario, en tanto que los límites entre diferentes tipos de capital son difusos.

Por último, para analizar si efectivamente se realizó un incremento de cada tipo de capital, los indicadores cuentan con tres estados: constante, iniciado y consolidado; caracterizados en la Matriz 2.

\section{Los procesos de acumulación de capital social y político.}

Para el análisis del proceso de incremento de los niveles acumulados de capital social y político, el grupo de cinco empresarios fue dividido a su vez en dos grupos: un primer grupo conformado por Juan, Jaime y Roberto (grupo A); y un segundo grupo el cual lo conforman Martha y Mario (grupo B).Las razones para realizar la anterior división radican en que, si bien las cinco historias cuentan con características socio-económicas diferentes en el momento de partida, los casos de Martha y Mario son sustancialmente diferentes al del grupo A. Ambos llegaron en condiciones específicas: el capital económico, político y social acumulado previamente en Colombia es reconocido y aceptado en las sociedades de llegada, que para este caso corresponden a Perú y Australia. Bajo este panorama, el grupo B disminuye la vulnerabilidad a experiencias de rechazo e incrementa las posibilidades de integración efectiva a la sociedad receptora. Muy por el contrario a las experiencias del grupo A, donde los capitales que traían consigo de Colombia no son reconocidos o el reconocimiento obtenido es precario. Así pues, el desarrollo del apartado se inscribirá en una lógica dual, la cual cuenta con un análisis segmentado a cada grupo y un análisis general que aplica para ambos casos.

Primer momento: la llegada.

Para cada uno de los casos seleccionados, tanto Roberto, Juan y Jaime como Mar-

\section{Matriz 2: Caracterización de los indicadores de los tipos de capital}

\begin{tabular}{|c|l|}
\hline Estado & \multicolumn{1}{|c|}{ Caracterización } \\
\hline Constante & $\begin{array}{l}\text { Este estado hace referencia a las variables estructurales de los sistema político, económico } \\
\text { y social,las cuales permanecen constantes durante todo el proceso y son independientes de } \\
\text { las variables instrumentales }\end{array}$ \\
\hline Iniciado & $\begin{array}{l}\text { Se ha iniciado el proceso de acumulación pero este se encuentra bajo formas precarias y } \\
\text { depende del contexto específico en el que se inscribe. No se cuenta con reconocimiento } \\
\text { social. }\end{array}$ \\
\hline Consolidado & $\begin{array}{l}\text { Los capitales cuentan con una base mínima necesaria y consolidada, se cuenta con } \\
\text { reconocimiento social y desarrollan lógicas propias para su utilización. }\end{array}$ \\
\hline
\end{tabular}


tha y Mario el momento de llegada trae consigo una carga psicológica de "dejar a un lado" su vida pasada en Colombia para iniciar una nueva por fuera del país. Sumado a lo anterior, estos colombianos se enfrentan a la categorización de su estadía como provisional en donde "su propia condición constituye un estado ambiguo que oscila entre la transitoriedad que les es atribuida y lo permanente de su proyecto migratorio. Esta doble condición que atraviesa, en general, los procesos migratorios contemporáneos, impele al inmigrante la dificultad de convivir y actuar en concordancia con este doble estado.De esta forma, se les exige que, en su vida cotidiana, cumplan con lo que le espera a una persona que se encuentra integrada permanentemente a la sociedad; a la vez que, tanto socialmente como de derecho, es portador de la desconfianza que emerge de su propia provisionalidad ${ }^{1}{ }^{1}$. Así mismo, tanto el grupo A como el B, se inscriben en lógicas transnacionales en donde establecen procesos simultáneos de identidad con la sociedad de origen y de integración con la sociedad receptora; lo que implica desdibujar los límites territoriales y temporales para el establecimiento de relaciones.

Sin embargo, debido a las características propias de cada sujeto entrevistado, como de las condiciones políticas, sociales y económicas del país de llegada, los procesos de acumulación de capital y las características que éstos adoptan en el primer momento son diferentes según cada grupo. Ahora, las diferencias radican principalmente bajo dos hechos

11 CAVALCANTI, Leonardo. El papel del protagonismo empresarial latinoamericano en la (re)construcción social de la categoría ‘inmigrante’ en España.En, Papers: revista de sociología, $\mathrm{N}^{\mathrm{o}}$ 85, 2007, p. 187. fundamentales: 1) el reconocimiento y aceptación del capital cultural que traen consigo desde Colombia y los usos que hacen de éste una vez llegan al país de acogida;2) las redes de familiares, amigos y/o conocidos que establecen y las formas como lo hacen. Ambos hechos inciden sustancialmente en las formas como se acumula tanto capital político, como capital social.

\section{El capital cultural.}

El capital cultural, el cual se refiere a los saberes profesionales, técnicos,empíricos y/o personales, constituye una variable fundamental para los procesos de integración efectiva a la sociedad receptora; así el manejo del idioma, el conocimiento de las prácticas sociales y culturales (como las tendencias en comportamientos) y el conocimiento profesional de una actividad influyen directamente sobre el número de experiencias de rechazo de los inmigrantes colombianos. Para el caso del grupo A (Jaime, Juan y Roberto), si bien los tres tienen una formación académica, el capital cultural que traen consigo desde Colombia es desconocido por parte de la sociedad receptora lo que los "obliga" a ocupar cargos para los cuales la mayoría de las veces están sobre-calificados en tanto que para su realización no se requiere formación profesional específica tales: como lavar baños, trabajos domésticos, trabajar como mesero en restaurantes, entre otros oficios. Así mismo, el capital simbólico de los integrantes de este grupo es bajo en la medida en que los otros tipos de capital no están legitimados y por tanto, no hay un reconocimiento de los mismos por parte de la sociedad de acogida. Con respecto a lo anterior Jaime afirma: "uno 
llega como un bebé, o sea, uno ni habla, ni oye, ni entiende, ni nada y a veces para dónde va la gente va uno...pues no hay ningún calor humano,la gente es muy fría, muy explotadora... obviamente a uno le toca llegar a trabajar en lo que le pongan y lo que le pongan es de todos los trabajos... esas cocinas de los restaurantes son una porquería...entonces es una cuestión de... como muy humillante, o sea, como que digo yo soy administrador de empresas, tengo un posgrado y había tenido medios para vivir bien... y llegar allá para que lo humillen unos campesinos sin nada de educación...uno tenerse que aguantar eso es muy berraco".

Podemos observar que, para el caso del grupo A, aunque técnicamente Roberto, Juan y Jaime tenían una formación específica, socialmente eran considerados siempre como trabajadores no calificados, puesto que en estos casos el inmigrante sólo existe para la sociedad receptora a partir del día que atraviesa sus fronteras; así pues se desconoce todo lo que antecede a esta existencia, incluso, su formación técnica [Cavalcanti, 2008: 219]. El caso contrario sucede con el grupo B. Mario termina sus estudios de pregrado en Australia por lo que el reconocimiento social del capital cultural profesional se realiza de manera casi inmediata; en cuanto a Martha ella es trasladada a la ciudad de Lima por la empresa con la que trabaja en Bogotá; por tanto no fueron desconocidos sus saberes técnicos. Para ambos casos, la integración al mercado laboral mediante la aplicación efectiva de sus conocimientos permitió a estos disminuir las experiencias de rechazo,si es que las hubo,y aumentar la aceptación de los mismos ante la comunidad receptora. Se observa, por tanto, que las formas en que son reconocidos socialmente los capitales de carácter cultural inciden directamente sobre los mecanismos de inserción, o integración, a la sociedad receptora a la vez que sobre el número de experiencias de rechazo.

Redes de familiares,amigosy/o conocidos.

El tema de las redes de familiares, amigos y/o conocidos es fundamental para ambos grupos en el momento de llegada. Sin embargo, la diferencia radica en que para el grupo A éstas redes influyeron en la trayectoria geo-espacial de los mismos. Las redes de inmigrantes permitieron determinar los costos y oportunidades que ofrecía cada lugar en donde decidían establecerse Roberto, Juan y Jaime; así para el caso de este ultimo la información suministrada a través de éstas relaciones le permitió, en un primer momento,llegar a Washington, posteriormente trasladarse a New York y finalmente instalarse de manera permanente en Miami; lo mismo sucedió con Jaime y Roberto.

Sin embargo, si bien influyen en las trayectorias de éstos, no son suficientes para determinar en dónde se ubicaron definitivamente, esta decisión estuvo atravesada también por las expectativas y motivaciones personales (qué buscan, por qué lo buscan, qué quieren hacer, cuál es su profesión, su vocación) y las oportunidades específicas del sistema económico, político y social en el cual se inscriben. Ahora, para ambos grupos estas redes de inmigrantes o de "solidaridad" se construyen en doble vía: en el sentido que ellos las utilizaron y a su vez ellos mismos crearon (o fortalecieron) redes con estas mismas características. Sin embargo, el modelo replica los estereotipos de los co- 
lombianos por lo que no era raro escuchar durante las entrevistas frases como: "uno trata de ayudar, pero tiene mucho cuidado a quién ayudar".

Con lo anterior se determinaron las diferencias sustanciales entre el grupo A y el B al momento de llegada, las cuales radicaban en torno a las formas en que era reconocido socialmente el capital cultural y los usos que se hacían de éste; y las redes de familiares, amigos y/o conocidos que establecían. Ahora bien, a continuación se analizará las formas en que estos hechos incidieron en los procesos de acumulación de capital político y social, y finalmente se analizarán las formas bajo las cuales se presentan cada uno de los capitales (indicadores).

En cuanto al capital cultural,el reconocimiento social o el desconocimiento del mismo incidió en las formas en que éstos eran percibidos por la sociedad receptora. Para el primer caso, el grupo A, el desconocimiento de los saberes técnicos de Roberto,Juan y Jaime determinó que ellos fueran asociados como trabajadores poco calificados. Por el contrario, en cuanto al grupo $\mathrm{B}$, el reconocimiento social de sus saberes profesionales permitió a estos integrarse en el mercado laboral ejerciendo su profesión casi de manera inmediata. Ahora bien, ambos fenómenos suscitaron procesos de socialización diferentes que incidieron sobre manera en la forma en que se acumulaba capital social, puesto que para el primer caso la acumulación se vio entorpecida por experiencias de rechazo y bajo nivel de integración a la sociedad receptora. Mientras que, para el segundo grupo,la acumulación de capital social se desarrolló desde una posición, llamémosla, privilegiada.
Ahora, en cuanto al capital político éste desarrolló una dinámica similar para ambos grupos. Tanto para el caso A como el B, la desconfianza en el establecimiento de redes de familiares, amigos $y / 0$ conocidos restringió la potencialización de recursos instrumentales de carácter privado en la lógica del grupo, bajo un panorama en el cual imperan las iniciativas individuales sobre las grupales. Así "el apoyo es restringido a las personas bien conocidas, mientras que la solidaridad colectiva se da sólo de manera esporádica esto es, en casos de tragedias naturales en el país o apoyo a compatriotas en casos de necesidad extrema. Un resultado de éste fenómeno es que, a pesar de su tamaño, las colonias de colombianos tienden a escapar de la atención de los gobiernos locales en el exterior (a no ser por las autoridades de seguridad) y por tanto a ser ignoradas en la toma de decisiones políticas que les afectan. Indiscutiblemente, esto aumenta la vulnerabilidad de los migrantes colombianos frente a la sociedad receptora en general, y en forma particular frente a empleadores, arrendadores de vivienda o profesores en las escenas públicas ${ }^{12}$. . Con respecto a lo anterior Jaime afirmaba en una de las entrevistas:

En un principio sí trataba de ayudar a las personas, porque eran colombianos...que estaban muy desubicados... si eran ciudadanos, para trabajar en esto tienes que ser ciudadano,yo trataba de guiarlos, mandarlos a la academia, yo mismo entrenarlos...y cuando ya estaban trabajando bien en forma, se volteaban y se iban... o se iban para otras compañías... mal agradecidos en otras palabras. No aprecian

12 guARnizo, Luis Eduardo, El Estado y la Migración Global Colombiana,en Migración y Desarrollo, primer semestre,número 006, Red Internacional de Migración y Desarrollo,Zacatecas, México, 2006, p.p. 285 - 286. 
las cosas, y al rato... ya regresan diciendo que se habían equivocado... que por favor... obviamente no todos ¿no? Pero sí la mayoría. Desafortunadamente hay mucho colombiano que llega con muchas ínfulas... aquí pueden ser lo que sean, el presidente de Ecopetrol si tú quieres, pero allá... no son nada. Pueden tener mucha experiencia, conocer mucho... pero si no tienen una muy buena palanca tienen que llegar como yo, a hacer lo que tienen que hacer... mientras progresan. Entonces ellos piensan que van a llegar allá a hacer lo mismo que hacían aquí y es imposible; entonces pierden mucho tiempo... se decepcionan, hasta que se dan cuenta que les toca trabajar en lo que salgan mientras que puedan ubicarse en algún trabajo que quieran hacer.

Así pues, al momento de llegada, el capital político y el social se encuentran expresados en la Matriz 3.

Momento número 2 y 3: creación y formación de la PYME; $y$ reconocimiento y consolidación de la misma.

El análisis de los momentos 2 y 3 he decidido realizarlos de manera conjunta en tanto que uno corresponde a la antesala del otro,se requiere para este punto observar el proceso de manera panorámica y no segmentada como en el caso del primer momento. Sin embargo,la caracterización de los indicadores de capital político y capital social se realizará por separado hacia el final de la sección. Aquí la lógica de los grupos A y B no será utilizada, se realizará en cambio el análisis conjunto del proceso de acumulación de capital político y capital social para los casos de las experiencias de éxito y se analizará por separado el caso específico de Juan. La razón para realizarlo de esta forma consiste en que las cuatro primeras personas corresponden a los casos de éxito empresarial, en tanto que las pequeñas y medianas empresa aún se mantienen en funcionamiento y cuentan con un amplio reconocimiento social. El caso de Juan, corresponde al caso opuesto, en tanto que las empresas de éste actualmente no tienen vigencia.

Ahora bien, para empezar, es importante señalar que durante el proceso de creación y formación de las PyMEs de estudio fueron fundamentales dos cosas: en primer lugar, el capital social acumulado previamente que les había permitido, por un lado, obtener reconocimiento social dentro de la sociedad receptora y por otro, conocer las lógicas del mercado y entablar relaciones con posibles consumidores de los productos o usuarios de los servicios. En segundo lugar,la acumulación de capital cultural de carácter técnico en el sector en el que posteriormente se ubicaría la empresa,

Matriz 3: Capital político y social al momento de llegada

\begin{tabular}{|c|c|c|c|}
\hline Variable & Dimensión & Indicador & Estado \\
\hline \multirow{2}{*}{ Capital Social } & Perspectiva pública & La ciudad & Constante \\
\cline { 2 - 4 } & Perspectiva privada & $\begin{array}{c}\text { Redes de familiares, } \\
\text { amigos y/o conocidos. }\end{array}$ & Iniciada \\
\hline Capital Político & Perspectiva pública & $\begin{array}{c}\text { El Consulado } \\
\text { El Estado receptor }\end{array}$ & Constante \\
\hline
\end{tabular}


por medio de la práctica en el mismo a través de trabajos que permitieran fortalecer los conocimientos adquiridos previamente de manera profesional.Con relación a lo anterior,durante las entrevistas realizadas a Roberto, Jaime, Mario y Martha se les preguntó sobre la forma en que había nacido la idea del restaurante,la agencia de seguridad privada, la agencia de intercambios estudiantiles y del café respectivamente; y fue común encontrar afirmaciones tales como: "como yo ya manejaba el tema" o "entonces un amigo me dijo", u otras tantas como "pues yo ya tenía clientes" o "yo tenía experiencia en eso".

La historia de Juan es un tanto diferente. La creación de las empresas (una agencia Inmobiliaria, un "car wash" y una gasolinera) se fue dando en la medida en que Juan "veía" una oportunidad de negocio. Esto se realizaba sin un previo conocimiento del mercado y sin la acumulación de capital cultural necesaria para gerenciar cada uno de las pequeñas y medianas empresas que fundaba. Sin embargo, si bien el capital social para este caso no se presenta como en los cuatros anteriores a manera de reconocimiento social y acumulación de redes sociales, éste aparece aquí bajo la forma de "asociaciones" con amigos que hacían parte de las empresas. Así pues, se observa que, tanto para los primeros casos de Roberto, Jaime, Martha y Mario, como para el segundo el capital social se utiliza de forma instrumental en la medida en que permite a cada uno de los actores desarrollar estrategias para la creación de la empresa, bien sea a través de potenciales clientes, o bien a través de asesorías o apoyos que reciben por parte de las redes sociales específicas.
Ahora bien,en cuanto al capital social en el tercer momento donde la empresa se encuentra consolidada y cuenta con cierto reconocimiento social, no hay muchos cambios significativos; este se mantiene constante bajo un mínimo necesario y en la mayoría de los casos se incrementa en tanto que aumentan el número de redes sociales de amigos, familiares y conocidos que son utilizadas con carácter instrumental y que les permiten consolidar su reconocimiento. En el caso de Juan, este no logra consolidar el capital social acumulado en la fase anterior y, sumado a factores externos, las empresas fracasan.

En la fase de creación de la empresa y el momento de llegada se observó que las relaciones tanto con el Consulado como con el gobierno receptor se limitaban a trámites legales; a excepción de Roberto el cual asistió a un centro comunitario del gobierno británico durante los primeros años de su estadía en Londres y el cual fue fundamental para el proceso de creación del restaurante yla acumulación de capital social y cultural. Ninguno de los demás recibió ayuda o asistencia por parte de ambas entidades o fue beneficiario de políticas o programas dirigidos a la población migrante; bajo este panorama fue especial encontrar que ellos se sentían "abandonados" por parte del gobierno colombiano mientras que nunca, dentro de su imaginario, esperaron algo por parte del Estado receptor. Con respecto a lo anterior,se le preguntó a los entrevistados si habían recibido algún tipo de ayuda por parte del gobierno colombiano durante la creación de la PYME y esto fue lo que respondió Mario:

Fue sólo entre mi socio yyo, con plata nuestra. Nosotros nunca pedimos ayuda ni nada [...] Tal vez porque no la necesitábamos, yo creo 
que todo gobierno tendrá algún tipo de ayuda, pero como no averiguamos nunca...entonces comenzamos a hacer nuestras cosas por si solos, tal vez nos hubieran ayudado... sí tal vez...pero la verdad es que no hemos recibido ningún tipo de asistencia, ahora es que me relaciono con el consulado colombiano, pero antes me limitaba a lo básico: a mantener mis papeles en orden, los trámites de la visa y esas cosas... pero nada más.

Es en este contexto bajo el cual aparece el capital político instrumental para Martha, Mario, Roberto y Jaime el cual está "basado totalmente sobre reconocimiento, el capital político es una forma particular de capital simbólico. Se puede comprenderlo como un crédito, basado en las múltiples operaciones de crédito con las que los actores prestan momentos de poder a una persona percibida como confiable gracias a su fiabilidad ${ }^{13}$ ". Ahora bien, “el capital político es una especie de capital reputacional ligado a la notoriedad, a la manera de ser percibido, al hecho de ser conocido y reconocido,y puede ser de dos tipo: personal o delegado, de acuerdo a la fuente de donde derive la fuerza de movilización que posee el agente considerado (...) este capital sólo puede ser conservado a costa del trabajo permanente que es necesario para acumular crédito y evitar el descrédito ${ }^{14 "}$. De manera que, el capital político instrumental se desarrolla en tanto que el reconocimiento social, adquirido por medio de la acumulación de capital social, es transformado en reconocimiento público en la medida

13 Meichsner,Silvia.El campo político en la perspectiva teórica de Bourdieu.En, Voces y Contextos, Ibero Forum, Primavera, Tomo 3, Volumen 2,2007, p. 14.

14 Amézquita, Constanza. Los Campos político y Jurídico en perspectiva comparada. Una aproximación desde la propuesta de Pierre Bourdieu. En Universitas Humanistica, No 65, Bogotá, Junio de 2008, p. 104. en que el Consulado los reconoce como actores significativos para la comunidad colombiana en el exterior y les otorga un tratamiento especial lo cual incrementa el número de acercamientos. Por otro lado, cada uno de los casos de estudio "utilizan" el capital político instrumental adquirido en función de la rentabilidad de la empresa,en donde si bien el consulado, y en general la comunidad colombiana en la sociedad receptora, representa un pequeño porcentaje del mercado, establecen relaciones de carácter comercial con el Consulado en tanto que les otorga un mayor reconocimiento. Por otro lado, en cuanto a la rentabilidad, afirman que para participar en política, si bien puede traer beneficios, se debe invertir bastante tiempo,el cual,o prefieren invertirlo en el mantenimiento de relaciones comerciales mucho más "jugosas" para el negocio, o no lo tienen por el mismo carácter de la empresa.

Antes de terminar, se aclara que el capital político instrumental aparece con relación al Consulado en tanto que este permite (condiciones estructurales) su utilización del reconocimiento social y público con el objetivo de aumentar los márgenes de rentabilidad. Por otro lado, las relaciones con el gobierno receptor se han mantenido estables, casi desde el primer momento de llegada, limitando los acercamientos a trámites legales; sin embargo, durante las entrevistas no se ahondó sobre este tema.

Observamos, por tanto, que los procesos de acumulación de capital económico, social y político durante los momentos identificados - momento de llegada, momento de creación de la pequeña y mediana empresa; y por último un momento de 
Matriz 4: Capital político y social para la fase de creación y formación de las pequeñas y medianas empresas

\begin{tabular}{|c|c|c|c|}
\hline Variable & Dimensión & Indicador & Estado \\
\hline \multirow{2}{*}{ Capital social } & Perspectiva pública & La ciudad & Constante \\
\hline & Perspectiva privada & Redes de familiares, amigos y/o conocidos. & Constante \\
\hline \multirow[t]{2}{*}{ Capital político } & Perspectiva pública & $\begin{array}{c}\text { El Consulado } \\
\text { El Estado receptor }\end{array}$ & Constante \\
\hline & Perspectiva privada & $\begin{array}{c}\text { "Yo tenía un amigo": capital social } \\
\text { instrumental }\end{array}$ & Iniciado \\
\hline
\end{tabular}

Matriz 5: Capital político y social para la fase de consolidación y reconocimiento de la PYME

\begin{tabular}{|c|c|c|c|}
\hline \multirow{2}{*}{ Variable } & Dimensión & Indicador & Estado \\
\hline \multirow{2}{*}{ Capital social } & Perspectiva pública & "La ciudad" & Constante \\
\cline { 2 - 4 } & Perspectiva privada & Redes de familiares, amigos y/o conocidos. & Constante \\
\hline \multirow{2}{*}{ Capital político } & Perspectiva pública & $\begin{array}{c}\text { El Consulado } \\
\text { El Estado receptor }\end{array}$ & Constante \\
\cline { 2 - 4 } & Perspectiva privada & $\begin{array}{r}\text { "Yo tenía un amigo": capital social } \\
\text { instrumental }\end{array}$ & Iniciado \\
\hline
\end{tabular}

reconocimiento posterior a la instalación de la PYME-son diferenciados para cada una de las experiencias; sin embargo, se observa la siguiente tendencia: el capital social aparece como el propulsor del capital político en tanto que a través del capital social adquieren reconocimiento público y social lo que aumenta su visibilización política y legitimación; sin embargo, el capital político aparece de forma instrumental en función de la rentabilidad de las empresas. Por otro lado, la aparición del capital de corte político no significa que dichos empresarios se involucren di- rectamente en política electoral; empero su atención recae sobre política de corte cívico y social.

"Ser" inmigrante: percepciones y configuración de la categoría

Ahora bien, las entrevistas realizadas a cada uno de los cinco empresarios permitieron observar una relación de carácter causa-efecto en donde la re-configuración de dicha categoría se da como resultado de la acumulación previa de capital económico, político, social y simbólico en tanto que legitima los otros tres capitales en la 
sociedad de acogida (aunque el capital simbólico no fue directamente tratado durante la investigación vale la pena nombrar su importancia). Por tanto, la “re-configuración” aparece como variable dependiente del proceso de acumulación de capitales. Por otro lado, es importante resaltar que la categoría de "inmigrante", entendiendo a ésta como condición social de unas personas respecto de las demás, no desaparece durante las trayectorias de vida para los casos de estudio; se mantiene constante el "encasillamiento" como inmigrantes colombianos, sin embargo, se alteran considerablemente los significados otorgados a dicha condición social.

Para el análisis de la re-configuración, es decir para observar los cambios en el tiempo del significado de la condición social, se parte del supuesto según el cual la categoría de "inmigrante" para el momento de llegada (antes de ser empresarios) se asocia con connotaciones negativas en la medida que, para la mayoría de los casos, se considera al inmigrante con la triada fuerza de trabajo, temporalidad y problema social ${ }^{15}$; lo cual limita su integración a la sociedad receptora. Así pues, para observar la re-configuración de la categoría se consideraron cuatro indicadores, los cuales permitieron observar si efectivamente "inmigrante" adquiere nuevas connotaciones para los casos de estudio una vez se han acumuladolos tres tipos de capital a través de la actividad empresarial; dichos indicadores son: reconocimiento social, reconocimiento político,liderazgo en la comunidad colom-

15 Cavalcanti, Leonardo. El papel del protagonismo empresarial latinoamericano en la (re)construcción social de la categoría 'inmigrante' en España” en Papers: revista de sociología, ISSN 0210-2862, № 85 , 2007 , pags. $177-191$. biana en el exterior, disminución en las experiencias de rechazo y sentimiento de inclusión efectiva en la sociedad receptora. Se espera entonces que, a mayor acumulación de capital político, económico y social, mayor nivel de reconocimiento social y político, menor número de experiencias de rechazo y aumento en el sentimiento de inclusión efectiva en la sociedad receptora; lo cual rompe con la triada anteriormente mencionada y altera los significados de la categoría de inmigrante. Así mismo, la atención recaerá sobre los casos de Martha, Roberto,Jaime y Mario en tanto que el caso de Juan no permite observar si la re-configuración se mantuvo constante o fue coyuntural en tanto que las empresas de éste fracasaron; aunque se observó que efectivamente sí hubo cierta acumulación no obstante la información recopilada en las entrevistas, $y$ el hecho del fracaso empresarial, no permite dar cuenta de la perdurabilidad de los capitales acumulados.

Y así llegaron. Son inmigrantes: temporalidad, fuerza de trabajo y problema social.

En la mayoría de los casos los inmigrantes al momento de llegada, principalmente aquellos que provienen de países en vía de desarrollo o subdesarrollados, son asociados con pre-concepciones de una categoría social fundada a través de imágenes de pobreza, marginalidad, delincuencia y toda una serie de condiciones que son impuestas [Cavalcanti,2008:219]. Así mismo, como se observaba en el capítulo anterior, el inmigrante sólo existe para la sociedad receptora a partir del día que atraviesa sus fronteras; así pues se desconoce todo lo que antecede a esta 
existencia,incluso, su formación técnica [Cavalcanti,2008,p.219]. Para los casos de estudio, al momento de llegada se confabularon las pre-concepciones asociadas a la categoría de inmigrante (temporalidad, fuerza de trabajo y problema social) con el desconocimiento de los capitales acumulados previamente en Colombia, principalmente el capital cultural, el político y el social; lo cual disminuyó su reconocimiento social y político, aumentó las experiencias de rechazo y disminuyó las capacidades de liderazgo en la comunidad colombiana en el exterior.Antes de continuar se debe aclarar lo siguiente: durante la investigación se analizaron los casos bajo dos escenarios; el primero de ellos consiste en la sociedad de acogida en general y el segundo el círculo social en el que se mueve el inmigrante, ahora el reconocimiento o desconocimiento en un escenario no influye necesariamente en el otro. Sin embargo, para efectos de ésta investigación el análisis recayó sobre el segundo escenario en tanto que el análisis se basa en percepciones personales de los empresarios con relación a su condición de inmigrantes.

Para los casos de Roberto, Juan y Jaime la anterior situación se refleja en el número de experiencias de rechazo y el bajo nivel de inclusión en la sociedad receptora. Con respecto a lo anterior, en una entrevista realizada a Jaime describió sus primer momento en Estados Unidos de la siguiente forma:

Empecé a buscar trabajo, trabajo y pues... conseguí en un restaurante que es lo único... cuando uno llega sin saber qué hacer, sin idioma y sin nada lo único es eso [...] Entonces bueno en Nueva York trabajé en restaurantes, en hospitales, cosas así... bien difíciles y humillantes.Pero bueno...como quiera yo aguanté y aguanté como por un año y ahí fue cuando me mudé a Houston, donde tenía otro amigo y él me dijo: pues véngase para acá,que acá esta como mejor y si no le gusta, pues se regresa. Y no, pues, fíjate que desde que llegué allá si me fue muy bien, me empezó a ir diferente, empecé a hacer cosas que yo quería hacer y empecé a buscar la manera de hacer cosas que me gustaran, me pagaran bien y no me tuviera que matar tanto.

Sin embargo, los casos de Mario y Martha son sustancialmente diferentes. Ambos llegaron a Perú y Australia respectivamente, con cierto capital económico, social y cultural acumulado previamente en Colombia el cual fue reconocido y aceptado por la sociedad receptora; por tanto las experiencias de rechazo fueron significativamente menores y el nivel de integración social fue mayor al momento de llegada. Así por ejemplo, Mario afirma que más que experiencias de rechazo por su condición de inmigrante colombiano en Australia, consistieron en problemas de comunicación y desinformación con respecto las características socio-económicas y políticas de Colombia:

\begin{abstract}
Australia es un país muy tolerante. Reciben bastante gente de todos lados y en especial en el sector educativo es el tercer mayor ingreso en la economía de ellos, entonces realmente rechazo y eso uno no siente, el racismo ¿no? Pues eso es lo que yo me doy cuenta; son muy tolerantes, aceptan nuevas culturas y de más...y eso es realmente...y claro en 2001 mucha gente no conocía realmente que es Sur América, Colombia ¿no?...Entonces uno era como un espejo de lo que era este país ¿no? Enseñándoles, aprendiendo ellos de uno y uno de ellos...pues, a veces no comprendían uno porque actuaba de una forma o de la otra... pero realmente rechazo no, solo era un problema de aprendizaje como diría yo.
\end{abstract}

Para el caso de Martha, al contrario que los casos de Roberto, Juan y Jaime, el hecho de ser inmigrante colombiano 
constituyó una variable que aumentó su margen de maniobra dentro del sistema económico y social peruano; afirmaba en una de las entrevistas que para la época en la que ella llegó a Lima no se asociaba a la categoría con la triada problema social, temporalidad y fuerza trabajo.

$\mathrm{Y}$ ahora son empresarios: re-configuración de la categoría "inmigrante" para los casos de estudio.

Si bien al momento de llegar la categoría de inmigrante se asocia con la triada temporalidad, problema social y fuerza de trabajo para los casos de Roberto, Juan y Jaime, el panorama cambia una vez son reconocidos como empresarios por la sociedad receptora; y la categoría "unifica" su significado para las cinco experiencias. Para todos los casos, en mayor o en menor medida según las experiencias particulares, la acumulación de capital económico, político y social les otorga reconocimiento público que les permite, a su vez, romper con los estigmas o preconcepciones impuestos por la sociedad receptora al momento de llegada; dicho reconocimiento se da bajo dos formas: por un lado sujeto a relación PYME-desarrollo y, por otro, asociado al capital político y social.

En cuanto al primer elemento, la actividad emprendedora de los inmigrantes - como en el caso de Roberto,Juan,Jaime, Mario y Martha- "promueve el desarrollo económico de zonas degradadas de la ciudad, creando una especie de proceso revitalizador en estos espacios, a través de mercados alternativos que poseen demanda y oferta propia... Además de revitalizar la zona donde estas actividades se instalan,las iniciativas empresariales de los inmigrantes también juegan un papel esencial en la reconstrucción de la condición social del inmigrante, aunque no siempre es reconocido como tal ${ }^{16 ”}$.Así mismo, "como personas que regentan diversas actividades emprendedoras, los inmigrantes empresarios, con su propia actividad, permiten cuestionar el "discurso impuesto" de la inmigración como un problema social ${ }^{17 "}$.A través de la creación de pequeñas y medianas empresas los inmigrantes asumen un papel protagónico en la escena pública y económica de la sociedad receptora [Cavalcanti, 2008: 230]; en donde la percepción de provisionalidad y de fuerza de trabajo, impuesta en un primer momento a la categoría de inmigrante, se cuestionan por la actividad emprendedora de éstos, los cuales no solo dinamizan la economía, sino que son potenciales empleadores y generadores de trabajo [Cavalcanti, 2008: 230]. Con respecto a lo anterior las percepciones de Roberto, con relación a su condición social de inmigrante colombiano, dan cuenta de que la actividad emprendedora realizada por éste permitió que él se sintiera "como uno más" en la sociedad inglesa a la vez que se sintiera productivo; así mismo facilitó a éste su reconocimiento:

Sí lo ayuda a uno a que la gente lo reconozca y a sentirse productivo ¿no?... yo tenía un trabajo digno antes, pero el restaurante me ha dado como estatus....además que le permite a uno progresar y ayudar a otros que llegaron como uno. Pero sí, yo me siento como uno más, yo creo que no hay mejor lugar para mí que Inglaterra... Además, que... pues el

16 Leonardo, Cavalcanti, "Negocios étnicos: importación y repercusiones de una categoría" en Retos Epistemológicos de las Migraciones Internacionales, Enrique Santamaría Lorenzo (Ed.), Anthropos, Barcelona, 2008, p. 224. 17 Ibíd.p. 228. 
restaurante está ubicado en un sector muy popular,en donde están varios bares y es una calle tradicional. Eso es bueno, porque todo el mundo lo ve.

Ahora bien, en cuanto al segundo elemento, el capital social acumulado por Roberto, Jaime, Mario y Martha les permitió consolidar redes sociales tanto con la comunidad de origen, como con la comunidad colombiana en el exterior y la sociedad "nativa" de las comunidades receptoras (a la vez que con otros inmigrantes de diferentes nacionalidades); lo cual promovió la integración efectiva al sistema social de llegada. Con lo anterior, cada uno de ellos disminuyó las experiencias de rechazo en tanto que aumentó su reconocimiento social como actores legítimos dentro del sistema social (en cuanto que empresarios). A su vez, dicho reconocimiento también se da en el plano del sistema político receptor en tanto que la mayoría de ellos obtienen el status de ciudadanos - a excepción de Martha que aún no ha iniciado los trámites - lo que aumenta el margen de maniobra de cada empresario dentro del mismo sistema.Así mismo el reconocimiento político se da con relación al sistema político colombiano, en este caso representado por el Consulado, el cual una vez se han consolidado las PYMEs, y han obtenido cierto grado de reconocimiento por parte de la comunidad colombiana en la sociedad receptora, incrementa su interés por aumentar los acercamientos y relaciones formales con dichos empresarios; paralelamente dota indirectamente a Roberto,Jaime, Mario y Martha de capital político instrumental. Por otro lado, las entrevistas permitieron observar que Roberto, Mario, Martha y Jaime asumen que dicho reconocimiento se le ha otorgado por las actividades rea- lizadas por su empresa; bien sea para los casos de los restaurantes (el de Roberto y el de Martha) o para los casos de las agencias de seguridad e intercambios (Jaime y Mario respectivamente).

\section{Conclusiones}

El capital social acumulado a través de las redes de familiares, amigos y/o conocidos permitieron a los empresarios seleccionados movilizarse dentro del sistema social y aumentar su reconocimiento dentro del mismo; y como resultado de lo anterior mejorar su posición jerárquica dentro de la estructura social de la comunidad receptora, lo cual amentó las posibilidades de éxito de la actividad emprendedora - en tanto dicho capital social permitió establecimiento de clientelas,socios y alianzas económicas. Ahora bien, el capital cultural es fundamental para la creación de empresa. Los saberes (profesionales o empíricos) fueron fundamentales para la consolidación de los proyectos de emprendimiento en tanto que permitieron a éstos establecer contactos que posteriormente se convirtieron en clientes, observar el comportamiento del mercado y diseñar estrategias para el posicionamiento dentro del mismo.

La frase "yo tenía un amigo(a)" aparece recurrentemente en las entrevistas realizadas a Roberto, Jaime, Juan, Mario y Martha; tener un amigo y/o conocido que trabajara en el consulado, o que en su defecto lo pusiera en contacto con alguien en el interior de éste, fue fundamental a la hora de entablar relaciones comerciales, más allá del simple papeleo al que estaban acostumbrados con el consulado. De esta manera el capital social determina para este caso la acumulación 
de capital político; el capital social es el que permite dar el paso inicial para el uso del reconocimiento social (previamente establecido y acumulado) para establecer relaciones con el Estado - para este caso los consulados - en función de intereses particulares (capital político instrumental). Ahora bien, el uso del capital político instrumental lo determina la rentabilidad derivada para los empresarios de dicha utilización, en donde las relaciones que establecen con el Consulado son, principalmente, de carácter comercial. Sin embargo, el Consulado, y en general la comunidad colombiana en el exterior, representa un pequeño porcentaje de la clientela de estas empresas. Por tal motivo, el consulado no es un aliado estratégico para ellos; aunque establecer relaciones comerciales con éste sí les otorga cierto reconocimiento. En cuanto a lo anterior, prefieren todos "invertir tiempo" en clientes que realmente sean significativos, aunque usan los recursos que el consulado les "presta" como por ejemplo publicidad en la página web. Un punto importante que hay que señalar es el hecho de que la identificación como “inmigrantes” es lo que les ha permitido el posicionamiento comercial de la empresa, servicios y/o productos que ofrecen. Sin embargo, este punto lo manejan con mucho cuidado en la medida en que no deben limitar el funcionamiento de la empresa a la comunidad colombiana, en la medida en que segmentan el mercado y no les da flexibilidad para expandirse en el mismo.

Por otro lado, la participación de capital económico, político y social se presenta de manera diferenciada según se encuentren en el primer momento de llegada, en el segundo espacio de forma- ción y creación de la PYME o en el tercer lugar de consolidación y reconocimiento de la misma.Se observa sin embargo,que paralelamente a la evolución empresarial de Roberto, Jaime, Juan, Mario y Martha se han ido incrementando los volúmenes de cada uno de éstos capitales; lo que a su vez facilitó el proceso mismo y amplio el margen de éxito de las actividades emprendedoras. Ahora bien, para los casos mencionados la puesta en marcha de pequeñas y medianas empresas impulsó la acumulación de capital de carácter económico,político y social y que, a su vez, alteró las percepciones que tienen éstos colombianos en el exterior con relación a su condición social como inmigrantes; en tanto que permitió aumentar su reconocimiento político y social, disminuir las experiencias de rechazo e integrarse efectivamente con la sociedad receptora a la vez que mantienen relaciones con la comunidad de origen.

Al inicio del documento se planteó la siguiente hipótesis: la puesta en marcha de pequeñas y medianas empresas por parte de los inmigrantes empresarios, seleccionados para la investigación, permite a estos incrementar los niveles acumulados de capital de carácter económico, social y político que afecta la manera como se configura la categoría de "inmigrante" para dichos empresarios. Para el desarrollo de lo anterior se plantearon tres objetivos específicos los cuales permitirían verificar la hipótesis propuesta; con relación a lo anterior se obtuvo:

Primero, una identificación de variables determinantes para la re-configuración de la categoría de inmigrante a partir de la creación de pequeñas y 
$\overline{\text { El inmigrante sólo existe }}$ para la sociedad receptora a partir del día que atraviesa sus fronteras; así pues se desconoce todo lo que antecede a esta existencia, incluso, su formación técnica

medianas empresas por parte de los casos seleccionados: durante el desarrollo de la investigación, contrastando la información recopilada en las entrevistas con la revisión bibliográfica, se encontró que el capital social aparece como piedra angular para la re-configuración de la categoría (es decir, para el significado de dicha condición social); sin embargo, el capital político desarrolla formas de legitimación pública y visibilización política que otorgan a dichos empresarios un mayor status en la estructura jerárquica del sistema social, lo que aumenta su margen de maniobra dentro del mismo. Por otro lado, el reconocimiento social de la labor ejercida por Roberto,Jaime,Mario, Martha y Juan (es decir, su condición de empresarios) se constituye como el elemento diferenciador de "otros" inmigrantes colombianos; lo que legitima la acumulación de capital cultural, económico, social y político. Ahora bien, dicho reconocimiento se inscribe tanto en la escena personal o privada como en la escena general o pública de la comunidad receptora. Por tanto como variables determinantes para la reconfiguración de la categoría de inmigrante para los casos seleccionados, a partir de experiencias de emprendimiento, se identificaron: en primer lugar el capital social y,seguido de lo anterior,el capital político derivado de éste; y en segunda instancia el reconocimiento público en ambas escenografías por parte del sistema político y social lo cual legitima los procesos de acumulación de capitales.

Segundo, un análisis del proceso de acumulación de capital económico, político y social: para la investigación el énfasis recayó sobre los procesos de acumulación de capital político; sin embargo, para observar dicho fenómeno fue necesario establecer un recorrido a través del proceso de incremento de los niveles acumulados de otros tipos de capital (cultural, social, simbólico y económico).Con relación a lo anterior,se observó que el capital político estructural, o la perspectiva pública de la variable, se mantiene constante durante los tres momentos identificados. La diferencia radica en la aparición del capital político instrumental el cual depende de la instrumentalización previa del capital social y el cual se encuentra determinado por la rentabilidad que produzca su utilización.

Tercero, un análisis de las redes transnacionales configuradas por los casos seleccionados: los cinco casos de estudio se encuentran atravesados por diversas redes transnacionales, en la medida en que mantienen vínculos con la comunidad de origen y la comunidad receptora. Para todos los casos, dichas redes fueron fundamentales para el primer momento de llegada; estas permitieron estudiar los costos y oportunidades del viaje y las posibilidades que ofrecía cada lugar donde se establecían. Así mismo, las redes transnacionales establecidas previamente desde Colombia influyeron en las experiencias 
de rechazo y los procesos de aceptación en la comunidad de acogida. Ahora bien, si bien es cierto lo anterior, dichas redes pierden importancia en el resultado final de la experiencia de emprendimiento la cual está determinada por el carácter del capital social y económico acumulado; empero se observa que alrededor de las pymes se construyeron nuevas redes transnacionales y/o se fortalecieron algunas previas.

El desarrollo de la investigación permitió verificar la hipótesis de manera positiva, en tanto que se comprobó que efectivamente la creación de pequeñas y medianas empresas permite incrementar los niveles acumulados de capital de carácter político, económico o social,los cuales influyen en las formas en que son percibidos por la sociedad receptora los casos seleccionados y los significados que adquiere para ellos la condición de inmigrante. Sin embargo, las actividades emprendedoras,su éxito o fracaso, dependen a su vez de los procesos de acumulación de dichos capitales; las formas en que estos procesos se presentan y los resultados que arrojan. Por tanto se habla de una lógica dual,en la que recíprocamente el montaje de PYMEs permite incrementar los niveles de diferentes tipos de capital; pero que a su vez dicho proceso de acumulación influye sobre el proceso de montaje de las diferentes pequeñasy medianas empresas. Ahora bien, el gradiente de incrementación de los niveles de capital depende del estado de consolidación y reconocimiento social con el que cuente la empresa; así pues, se encuentran diferenciados los grados acumulación para cada etapa de construcción y consolidación de la PYME.
Como reflexión final, cabe señalar que esta investigación corresponde a las primeras aproximaciones con respecto al tema; en donde debido a la riqueza de su información y lo valioso de su estudio, son necesarias nuevas y más profundas investigaciones con respecto a ésta problemática, es decir, sobre las actividades emprendedoras de los colombianos en el exterior y su impacto sobre la configuración política y social de éstos. Así mismo valdría la pena abordar otro tipo de actividades realizadas por los inmigrantes internacionales que permiten a éstos dicha configuración. Este trabajo, por tanto, corresponde a una pequeña mirada del amplio panorama sobre del estudio de los colombianos por fuera del país y las actividades emprendedoras que realizan; en donde si bien se da respuesta a la hipótesis planteada en un comienzo aparecen nuevos cuestionamientos frente a lo estudiado; por tanto se quedan sin resolver los siguientes puntos: de qué manera percibe la sociedad receptora la actividad emprendedora de Roberto, Jaime, Juan, Mario y Martha, cuál es la opinión del Estado colombiano frente al tema y cuál es la posición de los Estados de acogida con relación al reconocimiento público y social logrado a través de las actividades de emprendimiento. Así mismo, se debe tener en cuenta que dado el tamaño de la muestra que respondió el cuestionario,y la que posteriormente se utilizó como caso de estudio, las conclusiones aquí presentadas no tienen la fuerza de una generalización; por el contrario pueden tomarse como un sondeo de opinión exploratorio para posteriores investigaciones. 


\section{Bibliografía}

AMÉZquita,Constanza.Los Campos político y Jurídico en perspectiva comparada. Una aproximación desde la propuesta de Pierre Bourdieu, en Universitas Humanística, No 65, Bogotá, Junio de 2008.

Arango, Joaquín, La Explicación Teórica de las Migraciones: Luz y Sombra, Migración y Desarrollo, Red Internacional de Migración y Desarrollo, Universidad Autónoma de México, 2003.

BIDERBOST,Pablo; BOSCÁN, CARRASQUERO, Guillermo, "Inmigración y empresa en España:las dimensiones de una relación poco explorada", Instituto Interuniversitario de Iberoamérica, Universidad de Salamanca, Salamanca, 2008.

BIRNER, Regina, WITTNER, Heidi.Converting Social Capital into Political Capital. How do local communities gain political influence? A theoretical approach and empirical evidence frin Thailand and Columbia, Paper presented at the 8th Biennial Conference of the International Association for the Study of Common Property (IASCP), Indiana, June 2006.

Bourdieu, Pierre, Poder, Derecho y Clases Sociales, Las Formas de Capital: capital económico, capital cultura y capital social, Bilbao, Desclée De Brouwer, 2001.

BOURDIEU, Pierre (Autor), Kauf, Thomas (Traductor), Razones Prácticas: sobre la teoría de la acción,Anexo: la variante "soviética" y el capital político, Barcelona,Anagrama,2002. CODURAS, MARTÍNEZ,Alicia, "La Actividad Emprendedora de los inmigrantes en España 2005-2007" en El Papel de los Emprendedores en la Economía, No 841, Información Comercial Española ICE, abril de 2008, Madrid, p. 95-155.
COLEMAN,James (1990), Foundations of Social Theory, Belknap Press, Cambridge, Mass.

CÁRDENAS, Mauricio, MEJíA Carolina, Migraciones Internacionales en Colombia: ¿qué sabemos?, Working Papers Series, Documentos de Trabajo No.30,CEPAL,2006.

CAVALCANTi,Leonardo, "El papel del protagonismo empresarial latinoamericano en la (re)construcción social de la categoría “inmigrante" en España” en Papers: revista de sociología, ISSN 0210-2862, № ${ }^{0}$, 2007 , pags. 177-191

CAVAlCANTI,Leonardo, "Negocios étnicos: importación y repercusiones de una categoría" en Retos Epistemológicos de las Migraciones Internacionales, Enrique Santamaría Lorenzo (Ed.), Anthropos, Barcelona, 2008.

CONGRESO DE LA REPÚBLICA DE COLOMBIA, Ley 905 de 2004.

DURSTON, John, Qué es el Capital Social Comunitario, serie Políticas Sociales, División de Desarrollo Social, CEPAL, Santiago de Chile, junio de 2000.

ESPAÑOLA,R.A.(18 de Octubre de 2010).Diccionario de la Lengua Española.Obtenido de http:// buscon.rae.es/draeI/SrvltConsulta?TIPO_ $\mathrm{BUS}=3 \& \mathrm{LEMA}=$ categor $\% \mathrm{C} 3 \% \mathrm{ADa}$.

ESPañola, R. A. (15 de septiembre de 2010). Diccionario de la lengua española. Obtenido de http://buscon.rae.es/draeI/ SrvltConsulta?TIPO_BUS=3\&LEMA=fracaso.

GUARnizo, Luis Eduardo. El Estado y la Migración Global Colombiana, en Migración y Desarrollo, primer semestre, número 006, Red Internacional de Migración y Desarrollo, Zacatecas, México, 2006, p.p. 285 - 286.

INDA, G., \& DUEK, C. (2005). El concepto de las clases en Bourdieu: ¿nuevas palabras 
para viejas ideas? Aposta revista de Ciencias Sociales (23), 1 - 20.

MASSEY,Douglas; ARANGO,Joaquin; HUGO, Graeme; KOUAOUCI,Ali; PELlEGRINO,Adela; TAYLOR J. Edward. An Evaluation of International Migration Theory: The North American Case. Population and Development Review, Vol.20, No. 4 (Dec., 1994), pp. 699-751 ).

MEICHSNER,Sylvia, "El campo político en la perspectiva teórica de Bourdieu”, en Voces y Contextos,Primavera,Tomo3,Vol.2,2007,p.14. maya Agudelo, Gonzalo, Alternativas de Desarrollo Empresarial para la Pequeña y Mediana Empresa en Colombia: un enfoque de desarrollo endógeno de cara a la globalización, Universidad de Medellín, Facultad de Economía Industrial, Medellín, Colombia, 1999.

MÜLLER, Hans-Peter (1986): Kultur, Geschmack und Distinktion - Grundzüge der Kultursoziologie Pierre Bourdieus. en: Neidhardt, F./ Lepsius, M.R./ Weiß, J. [Ed.]: "Kultur und Gesellschaft" (cuaderno especial 27 de la Kölner Zeitschrift für Soziologie und Sozialpsychologie). Opladen: Westdeutscher Verlag, p. 162-190.

ocAMPO, José Antonio, "Migración Internacional y Desarrollo", en Colombia Nos Une, Memorias, II Seminario sobre Migraciones Internacional Colombiana y la Conformación de Comunidades Transnacionales, Fondo Editorial Ministerio de Relaciones Exteriores, Bogotá,2006, p.p 23 - 51.

ORLANDO, Pablo, Las PYMES y su rol en el Comercio Internacional, White Paper Series del Centro de Estudios para el Desarrollo Exportador - CEDEX, Universidad de Palermo,Argentina, 2006.

ORGANIZACIÓN INTERNACIONAL PARA LAS MIGRACIONES OIM, Glosario sobre Migración,
Derecho Internacional Sobre Migración, Ginebra, 2006.

PIORE,Michael.1979. Birds of Passage: Migrant Labor and Industrial Societies. Cambridge: Cambridge University Press.

PORTES, Aleandro, Convergencias Teóricas y Evidencias Empíricas en el Estudio del Transnacionalismo de los Migrantes, Internatial Migration Review, Transnacional Migration: International Perspectives, 2003.

PORTES,Alejandro; HALLER,William; GUARNIZO,Luis E, “Transnational Entrepreneurs: The Emergence and Determinants of an Alternative Form of Inmigrant Economic Adaptation" en American Sociological Review, Vol.67, No. 2 (Apr., 2002), pp. 278-298.

PRIES, Ludger,2002: Migración transnacionaly la perforación de los contenedores de Estados-nación.In: Estudios Demográficos y Urbanos (El Colegio de México), Vol. 17, Núm. 3, S. 571-597.

ROBInson, Rudi, Transnational Migrant Communities: Their Potential Contribution to Canada's Leadership Role and Influence in a Globalized World, Beyond The State Bounded Immigrant Incorporation Regime, The North-South Institute, Otawa, July 2005.

RODRÍGUEZ, Astrid Genoveva, La Realidad de la PyME colombiana. Desafío para el desarrollo, FUndEs, Fotolito Colombia Preprensa Digital, Colombia, 2003.

SUÁREZ NAVA, Liliana, "Lo transnacional y su aplicación a los estudios migratorios. Algunas consideraciones epistemológicas" en Retos Epistemológicos de las Migraciones Internacionales, Enrique Santamaría Lorenzo (Ed.), Anthropos, Barcelona, 2008, p.p $55-78$.

WORLD BUSINESS COUNCIL FOR SUSTAINABLE DEVELOPMENT WBCSD, Promoción 
de Pequeñas y Medianas Empresas para el Desarrollo Sostenible, Área de Desarrollo, Documento Informativo, Banco Mundial, Cáceres \& Cáceres, Quito, 2007.

zeVAllos, Emilio, Obstáculos al Desarrollo de las Pequeñas y Medias Empresas en América Latina, Fundación Para el Desarrollo Sostenible en América Latina, junio de 2006.

ZLOLNISKI,C. and CANALES,A.2001.Comunidades Transnacionales y Migración en la Era de la Globalización. Notas de Población No 73:221-252. Santiago de Chile, Chile. 